\title{
Pericardial tamponade as a fatal complication during atrial septostomy in the critically ill neonate with hypoplastic left heart syndrome and intact atrial septum: a case report as a viewpoint of a cardiac catheterization laboratory nurse
}

\section{Romana Palić*, Daniela Šmalcelj, Irena Ošlaj}

University of Zagreb School of Medicine, University Hospital Centre Zagreb, Zagreb, Croatia
KEYWORDS: cardiac catheterization, nurse, atrial septostomy, sternotomy. CITATION: Cardiol Croat. 2016;11(3-4):137. | DOI: http://dx.doi.org/10.15836/ccar2016.137

*ADDRESS FOR CORRESPONDENCE: Romana Palić, Klinički bolnički centar Zagreb, Kišpatićeva 12, HR-10000 Zagreb, Croatia. / Phone: +385-91-300-0315 / E-mail: romana.palich@gmail.com

ORCID: Romana Palić, http://orcid.org/0000-0003-0865-2049 • Daniela Šmalcelj, http://orcid.org/0000-0002-5137-9079 Irena Ošlaj, http://orcid.org/0000-0002-3538-0459

|IIIIIIIIIIIIIIIIIIIIIIIIIIIIIIIIIIIIIIIIIIIIIIIIIIIIIIIIIIIIIIIIIIIIIIIIIIIIIIIIIIIIIIIIIIIIIIIIIIIIIIIIIIIIIIIII

A critically ill female newborn with profound hypoxemia and acidosis was transferred from the county hospital with presumptive diagnosis of complex congenital heart disease. A hypoplastic left heart syndrome with double outlet right ventricle, restrictive ventricular septal defect and aortic coarctation was diagnosed in our institution by echocardiography and cardiac catheterization. ${ }^{1}$ Repetitive ventricular tachycardias with hemodynamic deterioration complicated catheterization procedure. In a dismal situation, atrial septostomy was performed. Because paroxysmal supraventricural tachycardia during balloon atrioseptostomy, the perforation of right atrium was caused by catheter manipulations. Followed by an abrupt loss of atrial pressure. Cardiac tamponade was recognized immediately and confirmed by echocardiography. Pericardial drainage was instituted right away, together with blood transfusions. An urgent sternotomy with surgical closure of punctured site was performed on the catheterization table. Only a transient hemodynamic stabilization followed, but eventually the baby died because of irretrievable cardiac arrest in spite of resuscitation efforts.

It has been known that neonatal mortality in the patients with complex heart defects with intact or highly restrictive atrial septum remains high despite successful urgent septostomy. ${ }^{1}$ Moreover, transcatheter creation of an atrial septal defect using conventional balloon atrial septostomy (with or without the combination of blade atrial septostomy) has an abysmal risk with additional complications, including arrhythmias and other cardiac performance leading to death. In such a situation, a highly professional team of competent and skilled nurses trained in highly demanding emergency procedures in cardiac catheterization laboratory is required.

We want to stress the necessity of proper education and training of nurses in the team performing demanding cardiac catheterization and surgical procedures in critically ill neonates and infants.

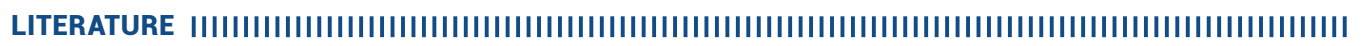

1. Vlahos AP, Lock JE, McElhinney DB, van der Velde ME. Hypoplastic left heart syndrome with intact or highly restrictive atrial septum: outcome after neonatal transcatheter atrial septostomy. Circulation. 2004;109(19):2326-30. DOI: http://dx.doi.org/10.1161/01.CIR.0000128690.35860.C5 